\title{
NOTE
}

\section{IBM PC laboratory software in Turbo Pascal}

\author{
GARY FINLEY \\ The University of Alberta, Edmonton, Alberta, Canada
}

A set of assembly language functions called TECIO.A (Finley, 1985) provides a software link between programs written in the C language and the Lab Tender IBM PC laboratory interface circuit board made by Tecmar, Inc. (6225 Cochran Rd., Solon, OH 44139-3377). I have recently translated the functions of TECIO.A into Pascal procedures and functions for use with the popular Turbo Pascal compiler sold by Borland International (4585 Scotts Valley Dr., Scotts Valley, CA 95066). The routines in TECIO.PAS are functionally identical to those of the TECIO.A package. They provide a simple mechanism for selecting the operating mode of the Lab Tender's three parallel ports, and they allow single-byte read and write operations with each port. The routines use the Lab Tender's multifunction timer chip to perform real-time clock functions with millisecond resolution. TECIO.PAS also provides for the input and output of ana-

The author's mailing address is: The University of Alberta, Psychology Department, Edmonton, Alberta T6G 2E9, Canada. log data using the Lab Tender's multiple-channel analogto-digital and digital-to-analog converters.

Using TECIO.PAS with Turbo Pascal Programs. The Turbo Pascal software environment has no provision for the linking of separately compiled software modules. This means that any application program that uses TECIO.PAS routines must tell the Pascal compiler to read the TECIO.PAS source code file at compile time. This is accomplished by placing a Turbo Pascal statement of the form " (\$ITECIO.PAS $\}$ " at the top of the application program source listing.

Availability of TECIO.PAS. The author will provide on request a printed listing of TECIO.PAS and some example Turbo Pascal programs that use these routines. The file will be copied to an IBM PC DOS format 5.25-in. floppy disk if one is included with the request. Either write to the author or use Bitnet electronic mail address: USERGFSO@UALTAMTS.

\section{REFERENCE}

FinLEY, G. (1985). Laboratory functions for the Tecmar Lab Tender and IBM PC. Behavior Research Methods, Instruments, \& Computers, 17, 397-398. 